\title{
The effects of taste extinction on ingestional potentiation in weanling rats
}

\author{
STEPHEN F. DAVIS \\ Emporia State University, Emporia, Kansas \\ MICHAEL R. BEST \\ Southern Methodist University, Dallas, Texas \\ CATHY A. GROVER \\ Texas A\&M University, College Station, Texas \\ and \\ SCOTT A. BAILEY, BOBBY L. FREEMAN, and MECHELLE A. MAYLEBEN
Emporia State University, Emporia, Kansas
}

\begin{abstract}
Four experiments investigated taste potentiation in weanling rats. In Experiment 1, the animals that drank a conditioning compound of denatonium and saccharin consumed significantly less on the test than controls that drank only saccharin during conditioning. This enhanced saccharin aversion was decremented by postconditioning extinction to denatonium in Experiment 2, and no generalization of saccharin aversions to the denatonium was observed in Experiment 3. Extinction of either saccharin or denatonium aversions after compound conditioning was shown in Experiment 4 to result in substantial decrements in aversions to the compound. The relationship of these outcomes to a multiple-association account of potentiation and to the role of discrimination processes in ingestional learning is discussed.
\end{abstract}

The aversiveness of one taste can be enhanced in rats if it is consumed in compound with a second taste prior to toxicosis. This phenomenon is known as taste potentiation and has been observed in both immature and adult rats (e.g., Bouton, Dunlap, \& Swartzentruber, 1987; Davis, Best, \& Grover, 1988; Kucharski \& Spear, 1984, 1985; LoLordo \& Droungas, 1989; Peterson, Valliere, Misanin, \& Hinterliter, 1985). Although the mechanisms that underlie taste potentiation have not been clearly isolated, it has been suggested that the processes contributing to this phenomenon in immature rats differ from those of adults (Kucharski \& Spear, 1984, 1985). Kucharski and Spear (1985) observed stronger taste potentiation in preweanling rats than in adults. They proposed that potentiated aversions to tastes in preweanling rats are due primarily to the increased salience of the compound and the tendency of these animals to confuse the iest element with the conditioning compound. If this account is true, an opportunity to discriminate the taste elements from the compound should eliminate the stimulus confusion that produced potentiation. Consistent with this prediction was the finding by Kucharski and Spear that exposure to one element of the compound after compound conditioning diminished the aversiveness of the second taste.

Correspondence should be addressed to Stephen F. Davis, Department of Psychology, Emporia State University, Emporia, KS 66801, or Michael R. Best, Department of Psychology, Southern Methodist University, Dallas, TX 75275.
There are, however, other accounts of this extinction effect. One is based on the assumption that potentiation results from the summation of multiple associations (e.g., Durlach \& Rescorla, 1980). Within the framework of this proposal, it is assumed that the two tastes are associated not only with the toxin US but also with each other. Consequently, the aversiveness of the potentiated taste is the summation of the two associations: the one between this taste and the US and the one between this taste and the second, also aversive, taste. From this perspective, extinction of the second or nontarget taste would be expected to weaken the association between the two tastes, thereby reducing the aversiveness of the target. This multipleassociation account has been particularly useful in organizing a variety of potentiation data collected from adult rats (e.g., Best, Batson, Meachum, Brown, \& Ringer, 1985; Davis et al., 1988; Durlach \& Rescorla, 1980).

Because the processes producing taste-mediated potentiation in weanling rats are still a matter for debate, our purpose in conducting these experiments was to replicate taste-mediated potentiation in weanling rats and to analyze its underlying mechanisms.

\section{EXPERIMENT 1}

Using a two-taste conditioning compound of denatonium saccharide (denatonium) and sodium saccharin, Davis et al. (1988) produced potentiated aversions to saccharin in adult rats. A similar design was used in the present ex- 
periment to determine if weanling rats were able to form potentiated aversions. In this experiment, animals in the critical experimental group twice received a mixture of denatonium and saccharin, followed by mechanical rotation. This means of inducing gastric malaise was used to prevent possible contaminations in weanling rats resulting from a pharmacological toxin. Saccharin aversions in the rats from this group were then compared with those of groups which drank either saccharin or water during conditioning.

\section{Method}

Subjects. Three litters of Holtzman rats $(n s=13,14,14)$ born in the Emporia State University vivarium served as subjects. All pups were housed in 10-gallon aquariums with a nursing dam until weaning (21 days). At this time all subjects were transferred to individual wire-mesh cages. Purina Laboratory Chow was available on a free-feeding basis for the duration of the experiment. As described below, a water-deprivation regimen was initiated during preference testing.

Apparatus. The conditioning apparatus consisted of a Lafayette (Model 13012) Color Mixer. An 8.25-cm (inside diam) plastic jar was mounted flush with the outside edge of the 20.32 -cm-diam rotating aluminum disc. The variable speed control allowed the number of revolutions per minute to be set at 180 . All preference testing took place in the home cage.

Procedure. When the pups were 1 day old, they were all placed in a communal aquarium and randomly reassigned to one of the nursing dams. In turn, each dam was randomly assigned to a specific treatment condition: $\operatorname{CON}(n=14), \operatorname{SAC}(n=13)$, and $\operatorname{MIX}(n=$ 14). Assignment was by litter, in order to avoid potential taste contamination between animals in the same aquarium.
Two conditioning experiences were administered, one at age 14 days and one at age 21 days. A conditioning session consisted of placing $.20 \mathrm{cc}$ of the designated fluid in the subject's mouth via a 1.0-cc syringe. Each subject was then placed in the plastic container and given a $1-$ min rotation period. At the completion of the rotation period the subjects were returned to the nursing dam (14 days) or an individual, suspended wire-mesh cage (21 days). Control animals (Group CON) were administered water on the two conditioning days. The single-element animals (Group SAC) were administered a . $15 \%$ saccharin solution on the conditioning trials, while the two-element animals (Group MIX) were administered a solution composed of $.15 \%$ saccharin and 1 part denatonium saccharide per 20,000 parts water. ${ }^{1}$

A 24-h recovery period followed the second conditioning session. During this time all animals were allowed free access to food and water. At the end of the recovery period, a fluid-deprivation regimen was begun. Four, daily, 10-min two-bottle preference tests (saccharin vs. water) were begun $24 \mathrm{~h}$ following the start of water deprivation. During preference testing, all fluids were presented in graduated $50-\mathrm{ml}$ centrifuge tubes fitted with spill-resistant sippers. The relative positions of the tubes containing saccharin and water varied randomly from day to day. All fluid consumption was recorded to the nearest $.50 \mathrm{ml}$. Experimental sessions were conducted at $0800 \mathrm{~h}$, while 10 -min supplemental water was provided at $1400 \mathrm{~h}$.

\section{Results and Discussion}

The percentage of subjects in each group that consumed a measurable amount of saccharin on each of the four days of preference testing is shown in Figure 1. Clearly, the percentage of subjects in Group MIX that consumed saccharin was lower than that of the two other groups on each of the four days of preference testing. In turn, fewer

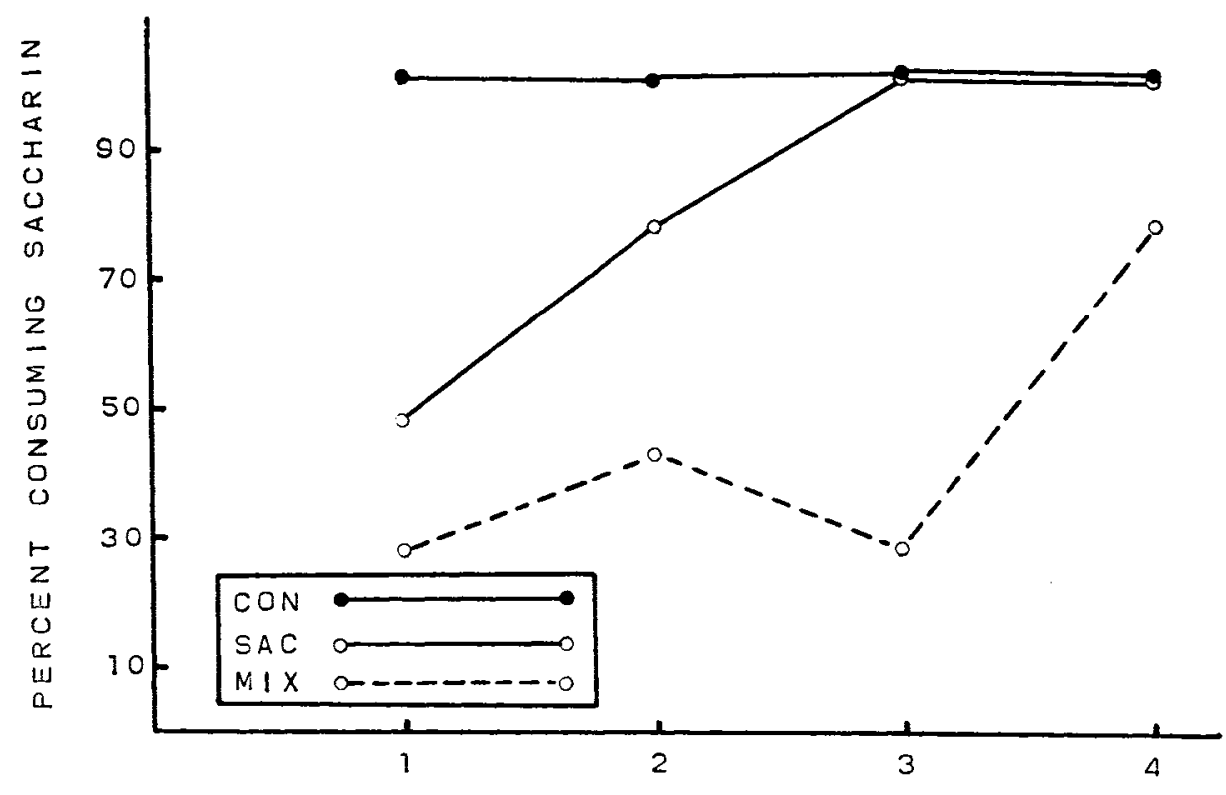

DAYS

Figure 1. The percentage of subjects in Groups CON, SAC, and MIX consuming a measurable amount of saccharin on each of the four days of preference testing in Experiment 1. On the two conditioning days, the animals in Group CON received water, those in Group SAC received saccharin $(.15 \%, w / v)$, those in Group MIX received a mixture of saccharin $(.15 \%$, w/v) and denatonium saccharide (1 part per $20,000, w / v)$. The unconditioned stimulus was mechanical rotation administered at $180 \mathrm{rpm}$ for one minute. 
animals in Group SAC consumed saccharin on Days 1 and 2 than did those in Group CON.

Because nearly three-fourths of the subjects in Group MIX failed to consume a measurable amount of saccharin on the first day of preference testing, the analysis-ofvariance assumptions of normality of distribution and homogeneity of variance were violated. Therefore, a series of $2 \times 2$ chi square tests was employed to evaluate these data. The distribution of animals that did and did not consume a measurable amount of saccharin was significantly related to the specific group on Days 1 and 2 when Groups CON and SAC were compared and on Days 1-4 when Groups CON and MIX were compared (smallest $\chi^{2}=3.94, p<.05$ ). It is clear from these outcomes that a taste aversion had been established. Reflecting the occurrence of potentiation, analyses of Groups MIX and SAC indicated that the distribution of the number of animals that did and did not consume a measurable amount of saccharin was significantly related to the specific group on all four preference tests (smallest $\chi^{2}=$ $4.58, p<.05) .^{2}$

It is apparent from the results of Experiment 1 that the saccharin aversions in Group MIX were significantly greater than those in the other two groups. This is a clear replication in weanling rats of the potentiation effects demonstrated in adult animals by Davis et al. (1988) using the same taste stimuli. Experiment 2 was designed to determine the resiliency of this enhanced saccharin aversion to postconditioning exposure to denatonium.

\section{EXPERIMENT 2}

Experiment 1 demonstrated taste-mediated potentiation in weanling rats. The purpose of the present experiment was to begin analyzing the associative structure of the elements in the conditioning compound. One useful manipulation for this purpose is an extinction procedure. If the rats in Experiment 1 formed associations between denatonium and saccharin, as well as between each taste and rotation-induced malaise, the potentiated aversion to saccharin should be undermined by nonreinforced presentation of denatonium following conditioning. To test this hypothesis, we gave the weanling rats the denatoniumsaccharin mixture to drink during conditioning and either denatonium or water following conditioning. Then they were tested on saccharin. If denatonium and saccharin had become associated with each other during conditioning, this extinction manipulation should interfere with this association and thereby reduce the aversion to saccharin.

\section{Method}

Subjects and Apparatus. Two litters of Holtzman rats $(N=22)$ served as the subjects for Experiment 2. The apparatus used in Experiment 1 also was used in Experiment 2.

Procedure. As in Experiment 1, all animals were randomly reassigned to a nursing dam at one day of age. In turn, the dams were randomly assigned to one of two treatment conditions: MIX-DEN and MIX-WAT. All subjects received two conditioning trials (identical to those of Experiment 1) to the denatonium-saccharin mixture.
Following a one-day rest period with free access to water, all animals were placed on fluid deprivation. On each of the five days following the start of fluid deprivation, subjects in Group MIXDEN were given 10-min exposure to denatonium during the experimental session, while subjects in Group MIX-WAT received 10-min access to water. This phase (extinction) was designed to extinguish the denatonium aversion in Group MIX-DEN.

The first of seven, two-bottle preference tests was begun $24 \mathrm{~h}$ following the completion of extinction. These tests were administered as in Experiment 1. Supplemental water was provided $6 \mathrm{~h}$ following each daily test session.

\section{Results}

Analysis of fluid consumption scores (ml) from the first and fifth days of extinction yielded significance for the groups $\times$ days $[F(1,20)=9.07, p<.01]$ interaction. Subsequent Newman-Keuls tests indicated that Group MIX-WAT $(M=19.33 \mathrm{ml})$ drank significantly $(p<.05)$ more fluid than Group MIX-DEN $(\mathrm{M}=$ $6.89 \mathrm{ml}$ ) on Day 1. However, the groups did not differ reliably on Day 5 (Group MIX-WAT, $\mathrm{M}=21.03 \mathrm{ml}$; Group MIX-DEN, $M=22.51 \mathrm{ml}$ ). This pattern of results indicates that the aversion to denatonium had been extinguished by Day 5 .

The mean consumption ratio for each of the two groups during preference testing is shown in Figure 2. These ratios were formed by dividing saccharin intake by total fluid intake (saccharin + water). Consistently lower ratios indicate stronger saccharin aversions. As can be seen from Figure 2, the consumption ratios of Group MIX-DEN were higher, reflecting weaker saccharin aversions, than those of Group MIX-WAT on all days of preference testing.

Analysis of these data corroborated this impression. The following factors achieved significance: groups $[F(1,20)$ $=8.82, p<.01]$, days $[F(6,120)=3.12, p<.01]$, and groups $\times$ days interaction $[F(6,120)=2.18, p<$ $.05]$. Subsequent Newman-Keuls tests indicated that the saccharin aversion of Group MIX-WAT was significantly $(p<.05)$ stronger than that of Group MIX-DEN on all days except Day 3.

The results of Experiment 2 are clear in demonstrating that the extinction of the denatonium aversion significantly weakened the saccharin aversion in Group MIXDEN. These results are consistent with others in pointing to the role of multiple associations in the production of taste potentiation. Durlach and Rescorla (1980) and Davis et al. (1988) noted similar effects in odor and taste potentiation procedures, respectively, and Best et al. (1985) reported analogous outcomes in the potentiation of environmental stimuli by taste (but see Lett, 1984).

The test-day data in this experiment also parallel those presented by Kucharski and Spear (1985) for preweanling rats. These investigators noted that a single postconditioning exposure to one of the tastes from the conditioning compound substantially diminished the aversion to the second element. Their interpretation of these results, however, was in terms of discrimination processes, not multiple associations. They argued that exposure to an element after conditioning allows the immature rat to dis- 


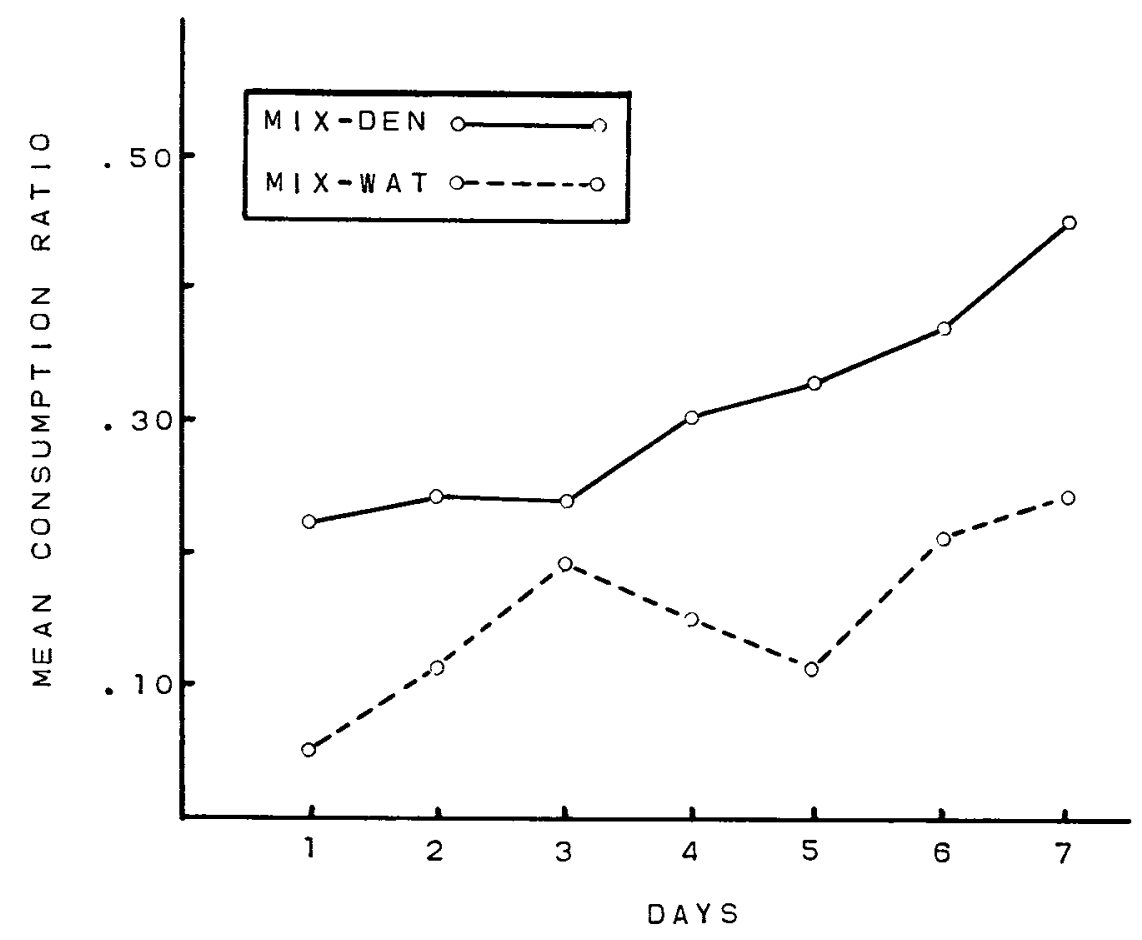

Figure 2. Mean consumption ratio (saccharin/saccharin + water) for Groups MIX-DEN and MIX-WAT during preference testing of Experiment 2. The rats in both groups drank the denatonium-saccharin mixture on each of two conditioning sessions. Extinction consisted of 5 10-min exposures to denatonium or water, respectively.

criminate the single elements from the compound and, therefore, prevents confusion of the individual tastes with the compound during testing.

It is not specified by Kucharski and Spear (1985) why exposure to one element after compound conditioning might allow the weanling rats to discriminate the other element from the compound. One possibility is that the establishment of different signal values for the two taste stimuli allows them to be more readily discriminated. But regardless of the mechanism or mechanisms for such discrimination, if postconditioning exposure to one of the elements of the compound allows the rats to discriminate between the taste elements of the compound, there should be little evidence of generalized aversions from one element to another after the aversion to the first has been extinguished. Evaluating generalization between the two tastes used in these experiments is also important for determining the viability of the multiple-association account of potentiation. It is possible that the decrement in saccharin aversion resulting from denatonium extinction is simply due to reduction in the aversiveness of the stimulus properties shared by these two tastes. Consequently, the role of generalized extinction in the outcomes of the present study was analyzed in Experiment 3.

\section{EXPERIMENT 3}

In the previous experiment, extinction of the denatonium aversion significantly interfered with the perfor- mance of the saccharin aversion. If denatonium and saccharin share stimulus properties, exposure to denatonium after conditioning to saccharin would be expected to reduce the aversion to saccharin. So that we could investigate the role of generalized extinction in this procedure, we gave the rats two saccharin-rotation pairings and then either denatonium or water prior to a saccharin test. Other rats drank water on the conditioning trials followed on subsequent days by denatonium or water. Saccharin aversions were then analyzed in all of these groups.

\section{Method}

Subjects and Apparatus. Two litters of Holtzman rats ( $\mathrm{ns}=$ $14,15)$ born in the Emporia State University vivarium served as subjects. The apparatus used in Experiments 1 and 2 also was used in Experiment 3.

Procedure. Twenty-four $\mathrm{h}$ following birth, the subjects were randomly assigned to a nursing dam, which, in turn, was randomly assigned to one of two primary treatments: animals conditioned following saccharin exposure $(n=15)$ and those conditioned following water exposure $(n=14)$. Conditioning was conducted in the same manner as in Experiments 1 and 2 . At the completion of conditioning, the subjects within each major treatment were randomly assigned to one of two subgroups: those that received denatonium exposure prior to preference testing and those that received water exposure prior to preference testing. Thus, Groups SAC-DEN $(n=7)$ and SAC-WAT $(n=8)$ were conditioned to saccharin and exposed to denatonium and water, respectively. Groups WAT-DEN $(n=7)$ and WAT-WAT $(n=7)$ were conditioned to water and exposed to denatonium and water, respectively. The postconditioning fluid-postexposure phase was begun $24 \mathrm{~h}$ following condition- 
ing. During this five-day, ad-lib phase, the fluid on each subject's cage was changed to coincide with its group designation. Because all bottles were weighed daily, it was possible to determine the amount of fluid (grams) that was consumed by each animal during each 24-h period.

At the conclusion of the fluid-postexposure phase, deprivation was begun by removing the fluids from all cages. A consumption baseline was established by measuring the amount of water consumed during a $15-\mathrm{min}$ session on each of the three following days.

A series of 5 daily, 15-min two-bottle (saccharin vs. water) preference tests was begun $24 \mathrm{~h}$ following the completion of the baseline period. During baseline and preference testing, all fluid consumption was recorded to the nearest $.50 \mathrm{ml}$. Supplemental water was provided $6 \mathrm{~h}$ following each daily session during baseline and preference testing.

\section{Results}

Fluid postexposure. A split-plot analysis of variance incorporating conditioning fluid (saccharin vs. water) and exposure fluid (denatonium vs. water) as between-subjects factors and days as a within-subjects factor was performed on the data from the fluid-postexposure phase. This analysis yielded significance for the conditioning fluid $[F(1,25)=6.13, p=.019]$, conditioning fluid $\times$ exposure fluid interaction $[F(1,25)=5.08, p=.031]$, days $[F(3,75)=15.31, p<.001]$, conditioning fluid $\times$ days interaction $[F(3,75)=3.39, p=.02]$, exposure fluid $x$ days interaction $[F(3,75)=4.04, p=.01]$, and conditioning fluid $x$ exposure fluid $x$ days interaction $[F(3,75)=2.78, p=.046]$.

Newman-Keuls tests, employed to probe the significant triple interaction, indicated that on Day 1 the saccharin conditioned animals exposed to denatonium (Group
SAC-DEN) drank significantly $(p<.01)$ less than did the saccharin conditioned animals exposed to water (Group SAC-WAT). Conversely, the water conditioned animals exposed to denatonium (Group WAT-DEN) consumed significantly $(p<.01)$ more of the exposure fluid (denatonium) than did the water conditioned animals exposed to water (Group WAT-WAT). By the conclusion of the fluid-postexposure phase, consumption did not differ reliably among the groups. In addition, the groups failed to differ on water consumption during the last two days of baseline $[F(3,25)=.456]$. This indicates that intake equivalence was established between the groups prior to the start of preference testing.

Preference testing. Mean consumption ratios for each of the four groups during preference testing are shown in Figure 3. The lower consumption ratios of the animals conditioned to saccharin (i.e., Groups SAC-DEN and SAC-WAT) indicated that these animals had consistently stronger saccharin aversions than did the animals in Groups WAT-DEN and WAT-WAT.

Analysis of these data yielded significance for the conditioning fluid $[F(1,25)=66.59, p<.001]$, days $[F(4,100)=5.72, p<.001]$, and conditioning fluid $x$ days interaction $[F(4,100)=3.61, p<.008]$. NewmanKeuls tests indicated that whereas Groups SAC-DEN and SAC-WAT did not differ reliably, they had significantly $(p<.01)$ lower ratios than did Groups WAT-DEN and WAT-WAT which, in turn, were not significantly different from one another. Finally, the ratios shown on Day 1 were significantly $(p<.01)$ lower than those shown on Day 5.

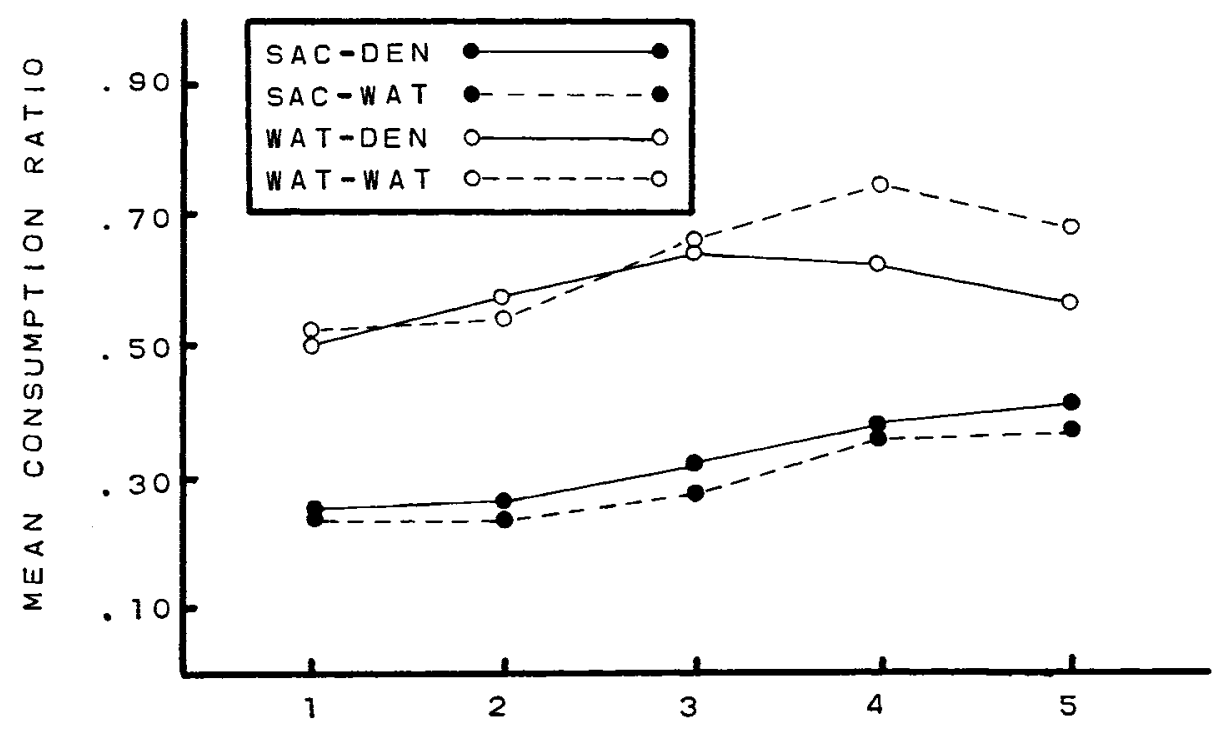

DAYS

Figure 3. Mean consumption ratios (saccharin/saccharin + water) for Groups SAC-DEN, SAC-WAT, WAT-DEN, and WAT-WAT during the preference tests of Experiment 3. Groups SAC-DEN and SAC-WAT received two saccharin-rotation pairings followed by 510 -min extinction exposures to denatonium or water, respectively. Groups WAT-DEN and WAT-WAT were treated identically except they drank water, rather than saccharin, during conditioning. 
The pattern of the test-phase data from Experiment 3 provides little evidence for stimulus generalization between saccharin and denatonium. Extinction of denatonium had no deleterious effect on either a previously conditioned saccharin aversion or on saccharin preference in animals with no prior saccharin experience. Clearly, any tendency for the rat to confuse the saccharin with denatonium was eliminated by the postconditioning exposure to denatonium.

The absence of a discernible role for stimulus generalization between saccharin and denatonium bolsters the credibility of a multiple-association account of the potentiation observed in Experiment 1. However, it might also be argued that the animals have a tendency to confuse the two tastes used in these experiments, but that the discrimination training provided by extinction allowed the animals to treat the tastes separately at the time of testing. It is this possibility that provided the focus for Experiment 4 .

\section{EXPERIMENT 4}

If the extinction manipulations used in Experiments 2 and 3 allowed the rats to discriminate the denatonium from the saccharin prior to testing, it could be argued that taste potentiation is a two-fold process, at least in immature animals. First, the salience of the compound is greater than that of the single elements because of the greater stimulus intensity of the two-element compound. Second, the heightened associative strength of the compound is transferred to the test element because the animals, lacking the discrimination training provided by the extinction of one element, confuse the test taste with the compound. If this account is true, postconditioning extinction of the taste elements should not attenuate the aversion to the compound. For one thing, the animals are being tested on the same stimulus with which they were conditioned. For another, the postconditioning exposure to one of the elements should foster a discrimination between that stimulus and the compound.

The outcomes implied by a multiple-association account of potentiation contrast with those of the discrimination position. Within the context of the multiple-association perspective, taste potentiation results from the summated associative strength of the test element. This is determined by the association between the test taste and the unconditioned stimulus, malaise, and between the test taste and the other aversive taste in the compound. These two aversive associations together combine for a greater aversion than that produced by pairing one of the tastes with the unconditioned stimulus. Therefore, extinction of the second taste should reduce its association with the US as well as reduce its association with the test taste. This, then, should reduce the aversiveness of the test taste and also the overall aversiveness of the two-taste compound.

The discrimination and the multiple-association accounts were investigated in Experiment 4. First, all four groups received two pairings of the denatonium and saccharin mixture with rotation. The animals in one group then received extinction with the conditioning compound.
Those in two others received either denatonium or saccharin extinction. The rats in the fourth group drank water during the extinction period. Testing was then conducted on the two-taste mixture.

\section{Method}

Subjects and Apparatus. Seventy-three Holtzman rats born in the Emporia State University vivarium served as subjects. At birth, all subjects were placed in a communal holding pen and then randomly redistributed to the 6 dams, such that 5 dams nursed 12 pups and 1 dam nursed 13 pups. Dams and litters were housed in 10gallon aquariums until the pups were weaned at 21 days. At this time all subjects were transferred to individual, wire-mesh cages. Purina Laboratory Chow was available on a free-feeding basis for the duration of the experiment. The apparatus used in Experiments 1-3 also was used in Experiment 4.

Procedure. Two episodes during which all animals were conditioned to the denatonium-saccharin mixture were administered in the same manner as in Experiments 1-3. Following the second conditioning session, four groups were randomly formed: WA $(n=$ $19)$, MX $(n=18)$, SA $(n=18)$, and DE $(n=18)$.

All subjects were given a one-day rest period following the second conditioning episode. A four-day extinction phase was begun $24 \mathrm{~h}$ after the rest day. During extinction, the subjects in each group were allowed free access to fluids in the home cage according to the following schedule: Group WA received water, Group MX received the denatonium-saccharin mixture, Group $S A$ received saccharin, and Group DE received denatonium.

Twenty-four $h$ following the conclusion of extinction, all animals were placed on a water-deprivation regimen that allowed them daily 20-min access to fluids. During the next three days, each subject was allowed access to water in order to establish a consumption baseline. On the final three days of the experiment, each subject received a 20 -min, two-bottle preference test (mixture vs. water).

During extinction, fluids were presented in standard, one-pint water bottles. Fluid consumption was measured to the nearest gram on a daily basis during this phase. During the consumption baseline and preference tests, fluids were presented in 50-ml centrifuge tubes and fluid consumption was measured to the nearest $.5 \mathrm{ml}$.

\section{Results and Discussion}

Analysis of variance of the extinction data yielded significance for the groups $[F(3,69)=11.92, p<.001]$, days $[F(3,207)=101.13]$, and groups $\times$ days interaction $[F(9,207)=2.11, p=.03]$. The Newman-Keuls procedure, employed to evaluate the significant interaction, indicated that Groups SA ( $M=21.78 \mathrm{~g})$, DE ( $M=$ $20.56 \mathrm{~g})$, and $\mathrm{MX}(\mathrm{M}=19.25 \mathrm{~g})$ did not differ among themselves, but consumed significantly less $(p<.05)$ fluid than Group WA $(\mathbf{M}=30.67 \mathrm{~g})$ on Day 1. All groups consumed significantly $(p<.01)$ more fluid on Day $3(\mathrm{M}=40.09 \mathrm{~g})$ than on Day $1(\mathrm{M}=23.06 \mathrm{~g})$. No other contrasts achieved significance.

Analysis of the final day of baseline consumption failed to yield a significant between-groups effect $[F(3,69)=$ $.823]$. Thus, the consumption levels of the four groups were equivalent prior to the start of preference testing.

Mean consumption ratios for each of the four groups for the three days of preference testing are shown in Figure 4. On Days 1 and 2, Group WA displayed stronger aversions than Groups DE and SA. Predictably, extinction of the aversive mixture prior to preference testing (i.e., Group MX) resulted in the highest consumption ra- 


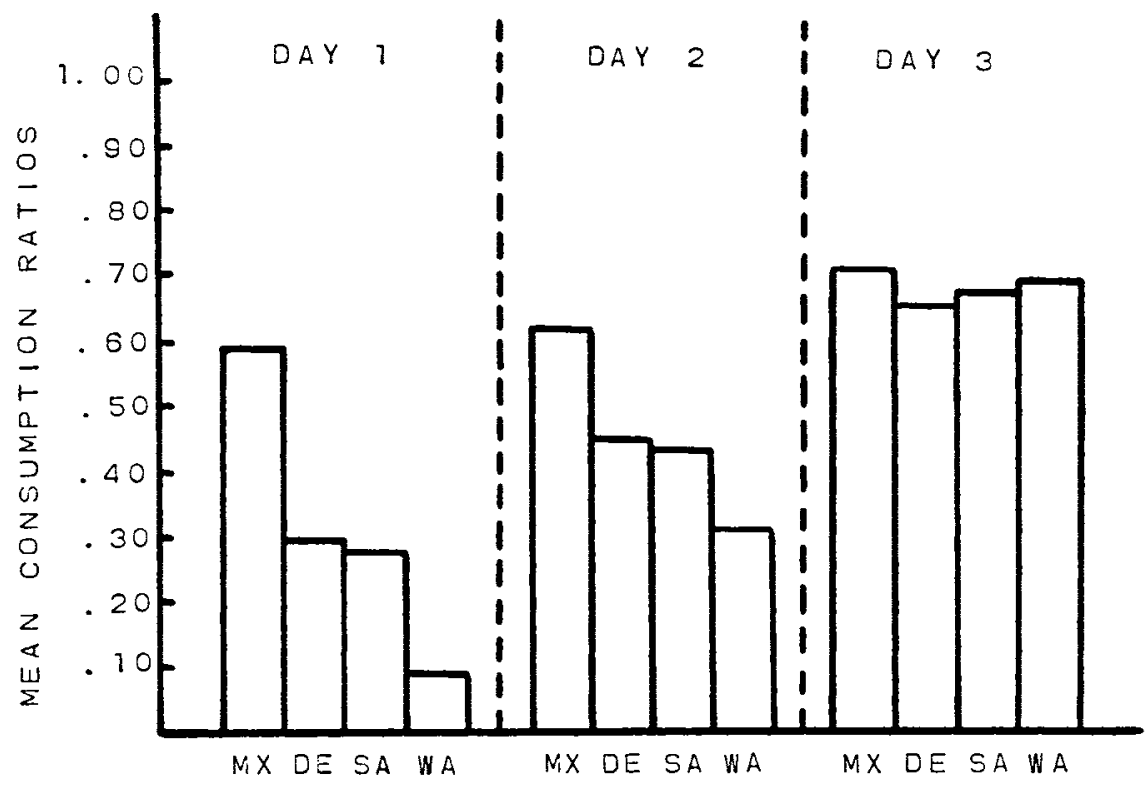

Figure 4. Mean consumption ratios (saccharin/saccharin + water) for Groups WA, MX, SA, and DE during the preference tests of Experiment 4. The rats in all groups received two pairings of the mixture with rotation during conditioning. Prior to testing the aversiveness of the mixture, Group WA drank water on 5 occasions for $10 \mathrm{~min}$, and Groups MX, SA, and DE drank the mixture, saccharin, and denatonium, respectively.

tios. Group differences had dissipated by the third day of testing.

Analysis of these data yielded significance for the groups $[F(3,69)=5.44, p<.01]$, days $[F(2,138)=$ $6.17, p<.01]$, and the groups $\times$ days interaction $[F(6,138)=3.89, p<.01]$. Subsequent Newman-Keuls tests indicated that consumption ratios were significantly higher $(p<.01)$ on Day 3 than on Days 1 and 2. Likewise, Day 2 ratios were significantly higher $(p<.01)$ than Day 1 ratios. All significant group contrasts were limited to Days 1 and 2 of preference testing. On each of these days, the consumption ratios of Group WA were significantly lower (Day $1, p<.01$; Day $2, p<.05$ ) than those of Groups DE, SA, and MX. The ratios of Groups SA and DE did not differ reliably on these days, but were significantly $(p<.05)$ lower than those of Group MX.

The finding of most importance in Experiment 4 was the diminished aversion to the compound evidenced by the animals in the groups extinguished with one of the elements. Both the DE and SA groups consumed significantly more saccharin than did Group WA, which drank water following conditioning with the compound. This interference with the aversion to the compound is not compatible with a discrimination account. Within this framework, postconditioning exposure to one of the elements should aid the animals in discriminating the element from the compound. If anything, this discrimination training should promote, rather than diminish, the aversion to the compound. In contrast, if, during conditioning, associations were formed between the two tastes, as well as between each taste and malaise, extinction of either element would be expected to reduce the overall aversiveness of the compound. This was the clear outcome of the preference tests in Experiment 4. Indeed, the reduction in aversion to the compound was similar and substantial after either denatonium or saccharin extinction.

\section{GENERAL DISCUSSION}

The series of experiments reported here demonstrates taste potentiation in weanling rats and replicates similar findings in both immature and adult rats (e.g., Bouton et al., 1987; Davis et al., 1988; Kucharski \& Spear, 1985). This potentiation phenomenon is significantly diminished by postconditioning exposure to the alternate element. Moreover, this extinction effect is not due to generalized extinction. Finally, postconditioning exposure to either element from the conditioning compound decrements the aversion to the compound.

Altogether, these results point to the role of multiple associations in the establishment of potentiation in weanling rats. It appears likely that one important feature of taste potentiation in these animals is the formation of associations between each taste in the compound and the unconditioned stimulus and of associations linking the two tastes. Such associations would be decremented by extinction manipulations and these decrements would be evident in subsequent responses both to the alternate stimulus and to the compound. The test results of Experiments 2 and 4 confirm this prediction.

The pattern of outcomes recorded in these experiments with weanling rats is similar to that seen in a variety of potentiation experiments using adult rats. Durlach and 
Rescorla (1980) were the first to report the deleterious effect on potentiated odor aversions of extinguishing the alternate taste element prior to testing (but see Lett, 1984, for the opposite result). Extinction-produced reductions of potentiation to environmental stimuli (Best et al., 1985) and to a second taste (Davis et al., 1988) have been reported. In conjunction with the present results, these additional studies indicate that multiple associations have a general relevance for the formation of potentiated ingestional aversions.

The bulk of the data in the present experiments also speaks to the importance of ingestional discrimination learning in the performance of taste aversions. The opportunity for discrimination learning provided by postconditioning exposure to a taste may be important in preventing generalized extinction (Experiment 3 ) and in contributing to decrements in potentiation of the nonextinguished element of a compound (Experiment 2). Indeed, it is worth noting in this context that opportunities for discriminating between flavors can reduce the magnitude of generalized aversions (Honey \& Hall, 1989) and that discriminating the context in which a taste is poisoned plays a key role in the control this taste exerts on ingestion (Batsell, personal communication, January 1990; Puente, Cannon, Best, \& Carrell, 1988). It is apparent from this body of work that familiarity with ingestional stimuli may reduce their general associability but does not diminish their significance to the organism.

The results of Experiment 4, however, prompt caution in attributing a disproportionate role to discrimination processes in the regulation of ingestion. Postconditioning exposure to either element of a two-element conditioning compound substantially reduced the aversiveness of the compound. This decrement would not be expected if exposure to the element aided in discriminating the conditioning compound from its constituent elements. This indicates that the control of ingestion is regulated not only by the various discriminations the animals make among the stimuli in the ingestional setting but also by the associations of the ingestional elements with each other and with their consequences.

It is also worth considering the implications of this work for the understanding of developmental changes in the formation of potentiated ingestional aversions. There is now considerable evidence that the parameters supporting tasteaversion learning differ between adult and immature rats, at least in part because of the more rudimentary processing and memorial capability of younger animals (Spear \& Kucharski, 1984a, 1984b). This may prove true in the case of potentiated aversions as well. In this regard, Kucharski and Spear (1985) propose that immature rats develop apparently potentiated taste aversions because they confuse the test element with the compound on which they were conditioned. The results of these experiments, however, argue against this. The outcomes of Experiment 4 are particularly problematic for this interpretation, demonstrating that the aversion to a two-taste compound is reduced by postconditioning exposure to either element. Interestingly, a careful look at the data from Experiment 2A of the Kucharski and Spear (1985) paper also reveals some decrements in the aversion to a compound after the extinction of either of its constituent tastes. This indicates that the stronger potentiation evidenced in immature rats compared with adults (Kucharski \& Spear, 1985; Peterson et al., 1985) is probably due to processes other than the young animals' tendency to mistake the test element for the conditioning compound (cf. Peterson et al., 1985).

It is also unlikely that stimulus confusion is the mechanism producing most instances of taste-mediated potentiation in adult rats. This is particularly apparent in those cases where taste stimuli enhance the conditioning of such exteroceptive stimuli as the environmental context (Best, Batson, Meachum, Brown, \& Ringer, 1985; Best, Brown, \& Sowell, 1984; Best, Davis, \& Grover, 1989; Best \& Meachum, 1986), auditory stimuli (Ellins \& von Kluge, 1987), or the visual properties of food (Galef \& Osborne, 1978). There is little chance of the rat confusing the exteroceptive properties of an ingestional setting with the taste of the edible in that setting.

Finally, it is worth noting that the first accounts of ingestional potentiation focused on its adaptive function in the feeding system. Garcia and his colleagues (e.g., Garcia \& Hankins, 1977; Palmerino, Rusiniak, \& Garcia, 1980; Rusiniak, Hankins, Garcia, \& Brett, 1979) emphasized the ability of distal feeding cues, such as odor, to become conditioned at levels comparable to taste cues when the two occur together in an ingestional setting. A decade of work on ingestional potentiation has served only to reinforce the biological significance of these phenomena. Most legitimate instances of potentiation result from toxicosis conditioning and require taste mediation. The regularities surrounding the various potentiation phenomena and their specificity to ingestional settings suggest that they serve similar, if not identical, functions in both young and adult rats.

\section{REFERENCES}

Best, M. R., Batson, J. D., Meachum, C. L., Brown, E. R., \& RINGER, M. (1985). Characteristics of taste-mediated potentiation in rats. Learning \& Motivation, 16, 190-209.

Best, M. R., Brown, E. R., \& Sowell, M. L. (1984). Taste-mediated potentiation of noningestional stimuli in rats. Learning \& Motivation, 15, 244-258.

Best, M. R., Davis, S. F., \& Grover, C. A. (1989). Straight alley extinction performance is disrupted by taste-aversion conditioning. Learning \& Motivation, 20, 358-372.

BeST, M. R., \& MEACHUM, C. L. (1986). The effects of stimulus preexposure on taste-mediated environmental conditioning: Potentiation and overshadowing. Animal Leaming \& Behavior, 14, 1-5.

Bouton, M. E., Dunlap, C. M., \& Swartzentruber, D. (1987). Potentiation of taste by another taste during compound aversion learning. Animal Learning \& Behavior, 15, 433-438.

Davis, S. F., Best, M. R., \& Grover, C. A. (1988). Toxicosis-mediated potentiation in a taste/taste compound: Evidence for within-compound associations. Learning \& Motivation, 19, 183-205. 
Durlach, P. J., \& Rescorla, R. A. (1980). Potentiation rather than overshadowing in flavor-aversion learning: An analysis in terms of within-compound associations. Journal of Experimental Psychology: Animal Behavior Processes, 6, 175-187.

Ellins, S. R., \& von Kluge, S. (1987). Preexposure and extinction effects of lithium chloride induced taste-potentiated aversions for spatially contiguous auditory food cues in rats. Behavioral Neuroscience, 101, 164-169.

GaleF, B. G., \& OsBorne, B. (1978). Novel taste facilitation of the association of visual cues with toxicosis in rats. Joumal of Comparative \& Physiological Psychology, 92, 907-916.

GarCia, J., \& Hankins, W. G. (1977). On the origin of food aversions. In L. M. Barker, M. R. Best, \& M. Domjan (Eds.), Learning mechanisms in food selection (pp. 3-19). Waco, TX: Baylor University Press.

Honey, R. C., \& Hall, G. (1989). Enhanced discriminability and reduced associability following flavor preexposure. Learning \& Motivation, 20, 262-277.

Kucharski, D., \& SPEAR, N. E. (1984). Potentiation of a conditioned taste aversion in preweanling and adult rats. Behavioral \& Neural Biology, 40, 44-57.

Kucharski, D., \& Spear, N. E. (1985). Potentiation and overshadowing in preweanling and adult rats. Journal of Experimental Psychology: Animal Behavior Processes, 11, 15-34.

LETT, B. T. (1984). Extinction of taste aversion does not eliminate taste potentiation of odor aversion in rats or color aversion in pigeons. Animal Learning \& Behavior, 12, 414-420.

LoLordo, V. M., Droungas, A. (1989). Selective associations and adaptive specializations: Taste aversions and phobias. In S. B. Klein \& R. R. Mowrer (Eds.), Contemporary learning theories: Instrumental conditioning theory and the impact on biological constraints on learning (pp. 145-179). Hillsdale, NJ: Erlbaum.

Palmerino, C. C., Rusiniak, K. W., \& Garcia, J. (1980). Flavorillness aversions: The peculiar roles of odor and taste in memory for poison. Science, 208, 753-755.
Peterson, C. S., Valliere, W. A., Misanin, J. R., \& Hinterliter, C. F. (1985). Age differences in the potentiation of taste aversion by odor cues. Physiological Psychology, 13, 103-106.

Puente, G. P., Cannon, D. S., Best, M. R., \& Carrell, L. E. (1988). Occasion setting of fluid ingestion by contextual cues. Learning \& Motivation, 19, 239-253.

Rusiniak, K. W., Hankins, W. G., Garcia, J., \& Brett, L. P. (1979). Flavor-illness aversions: Potentiation of odor by taste in rats. $B e$ havioral \& Neural Biology, 25, 1-17.

SPEAR, N. E., \& KuChARSKI, D. (1984a). Ontogenetic differences in the processing of multi-element stimuli: Potentiation and overshadowing. In H. Roitblat, T. Bever, \& H. Terrace (Eds.), Animal cognition (pp. 545-568). Hillsdale, NJ: Erlbaum.

SPEAR, N. E., \& KuCharSKI, D. (1984b). Ontogenetic differences in stimulus selection during conditioning. In R. V. Kail \& N. E. Spear (Eds.), Memory development: Comparative perspective (pp. 227-252). Hillsdale, NJ: Erlbaum.

\section{NOTES}

1. The flavors and concentrations used in all experiments in this report were identical to those employed by Davis et al. (1988).

2 . In order to place these data and the consumption-ratio data reported in Experiments 2-4 in better perspective, analyses of total fluid consumption recorded during preference tests also were performed. In no instance was a significant between-groups effect obtained [largest $F(3,69)=1.77, p>.10$, Experiment 4$]$. Thus, the results of the various preference tests were not influenced by differential fluid consumption.
(Manuscript received February 23, 1990; revision accepted for publication June 18, 1990.) 